\title{
Electrical Machines and Power Electronics for Starter-Generators in More Electric Aircrafts: A Technology Review
}

\author{
Jonas Kristiansen Nøland ${ }^{1 *}$, Matteo Leandro ${ }^{2}$, Jon Are Suul ${ }^{3,4}$ Marta Molinas $^{4}$ and Robert Nilssen ${ }^{1}$ \\ ${ }^{1}$ Department of Electric Power Engineering, Norwegian University of Science and Technology, Trondheim, Norway \\ ${ }^{2}$ Department of Industrial Engineering, University of Padova, Padova, Italy \\ ${ }^{3}$ SINTEF Energy Research, Trondheim, Norway \\ ${ }^{4}$ Department of Engineering Cybernetics, Norwegian University of Science and Technology, Trondheim, Norway \\ *E-mail: jonas.k.noland@ntnu.no
}

\begin{abstract}
Safety-critical power conversion systems play a major role in the paradigm shift towards more electric aircraft (MEA) architectures. This paper reviews the electrical machines and their power electronic systems that are currently competing in the application of integrated starter-generators (S/Gs) in MEA power systems. Motivated by the strict requirements of sufficient electrical starting capability, super-high power density and ultra-high reliability, additional considerations on the overall system design are necessary, including the power electronic converters (PECs) and integrated thermal designs. These aspects are discussed not only in the light of their many benefits but also of the challenges introduced by the continuous advancements and emerging innovations in the power conversion technology. In achieving the MEA goals and capitalize on all potential benefits, optimization-based design approaches will be necessary, where the aggregation of electric machines, PECs and the aircraft grid is considered as an integrated system to be optimized. This review highlights the importance of these aspects and offers a view on future perspectives and open issues.
\end{abstract}

Index Terms-Aircraft power generation, more-electric aircraft (MEA), starter-generator (S/G).

\section{INTRODUCTION}

Over the last decades, the ongoing electrification of aircraft power systems has become an important research topic. The move towards more electric and all-electric aircraft has been motivated by the aim of reducing the fuel consumption by reducing the total weight and optimizing the management of electrical power on board, while increasing the reliability and safety [1], [2]. The integrated starter-generator $(\mathrm{S} / \mathrm{G})$ is considered as one of the core technologies in the more electric aircraft (MEA) paradigm (from the early 1990s). In this initiative, the S/Gs are electrically configured to start the engine in starting mode ("engine cranking") and convert mechanical power from the engine in generator mode. In this way, they replace conventional hydraulic- and pneumatic systems. Fig. 1 illustrates the S/G concept, where two main paradigms in the electrification of aircraft systems are shown, depending on whether the $\mathrm{S} / \mathrm{G}$ is integrated to an ac or dc distribution grid.

In this paper, the electrical machines and corresponding power electronic solutions for S/G applications in MEA sys- tems is reviewed. First, section II is briefly discussing the general development trends towards MEA systems, the basic principles and requirements of $S / G$ applications and their power electronic interfaces to the MEA power distribution grid. Section III discusses the performance of the Wound Field Synchronous Machine (WFFSM) as a S/G, including the excitation systems required for S/G applications. Furthermore, Section III describes the main alternatives to the WFSM, including Induction Machines (IMs), Permanent Magnet Machines (PMMs), and Switched Reluctance Machines (SRMs). Finally, Section IV presents the key points of this paper in a table and then concludes the paper presenting future perspectives.

\section{POWER CONVERSION AND DISTRIBUTION SYSTEMS FOR STARTER-GENERATORS IN MEA APPLICATIONS}

The motivations for the development towards MEA concepts, the established alternative power distribution systems and the available power electronic conversion (PEC) technology has been thoroughly covered in other recent publication [3]-[7]. However, a brief introduction to the requirements for MEA power systems, the operation principles for S/Gapplications and the PEC interfaces for various S/G concepts is presented in the following.

\section{A. Requirements for MEA applications}

The requirements and the operating conditions of aircraft power generation are fundamentally different from groundbased machines. In aerospace S/G-applications, low machine weight, high power capability and high power density are among the key requirements. Consequently, high air gap flux densities and high armature current density are two possible solutions. As a result, the thermal management system becomes important [8] and the hot spots in the power conversion systems have to be carefully considered in the design. In addition, fault-tolerant operation and insulation management [9] are key issues.

The ongoing electrification of aircraft engines is a result of the continuous advancements and innovations in both power 


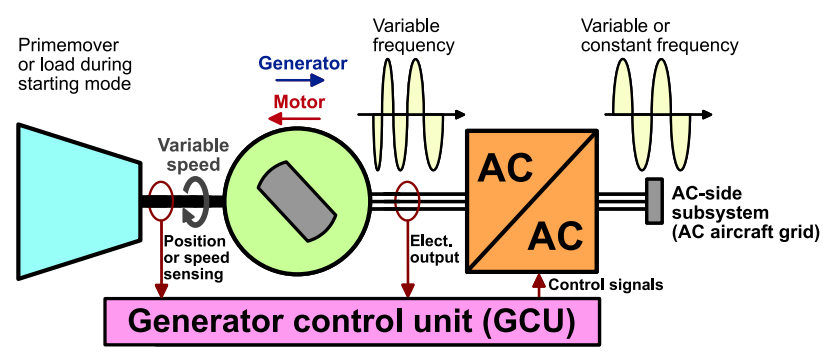

(a)

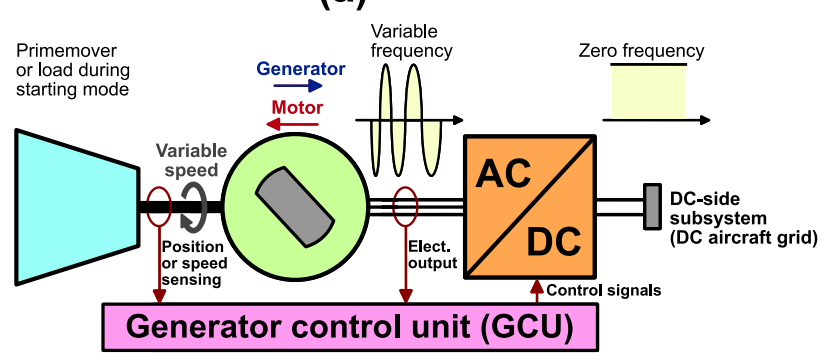

(b)

Fig. 1. Two paradigms for electric start in the MEA initiative. a) variable speed constant frequency (VSCF) or "frequency-wild" ac distribtuion. b) interface to a dc distribution system

electronic converters (PECs) and electrical machine designs [10]. Another driver is the advancements in closed-loop control of speed and torque, including using position sensor-less algorithms that eliminate the need of sensors and by that increases reliability [11], [12].

As a result of this development, the installed electrical power capacity in aircraft has grown exponentially during the last two decades [3]. In fact, the maximum power of the WFSM type reaches $250 \mathrm{kVA}$ and has been used in Boeing 787 Dreamliner platform (four equally rated WFSMs) [13], which has a total of $1450 \mathrm{kVA}$ electrical power. The new engines were developed by GE and Rolls Royce, and they present two of the so-called variable frequency starter generator (VFSG) on two of the main engines [14].

The on-board power system architecture has also experienced recent changes. Traditionally, a direct-on-line (DOL) constant speed constant frequency (CSCF) system has been widely used, like Boeing B777 and Airbus A340 [15]. However, the mechanical constant speed drive (CSD) is a complex, heavy and large system, and performs with poor conversion efficiency and low reliability [16]. In parallel to this paradigm, variable speed constant frequency (VSCF) systems employing cycloconverters or dc-links have been utilized in military aircrafts like F-18, AV-8B, TR-1 and F117 etc [17]. For typical VSCF systems, $115 / 200 \mathrm{~V}$ and $400 \mathrm{~Hz}$ has been the technology standard [3]. Recently, the variable speed variable frequency (VSVF) system has attracted attention ("frequency-wild ac system"), where Airbus A380 was the first commercially available product in this category, employing four 120/150 kVA VF generators. Not long ago, a "variable-voltage" bus system has been proposed to optimize the power flow [18]. Furthermore, dc-distribution systems with

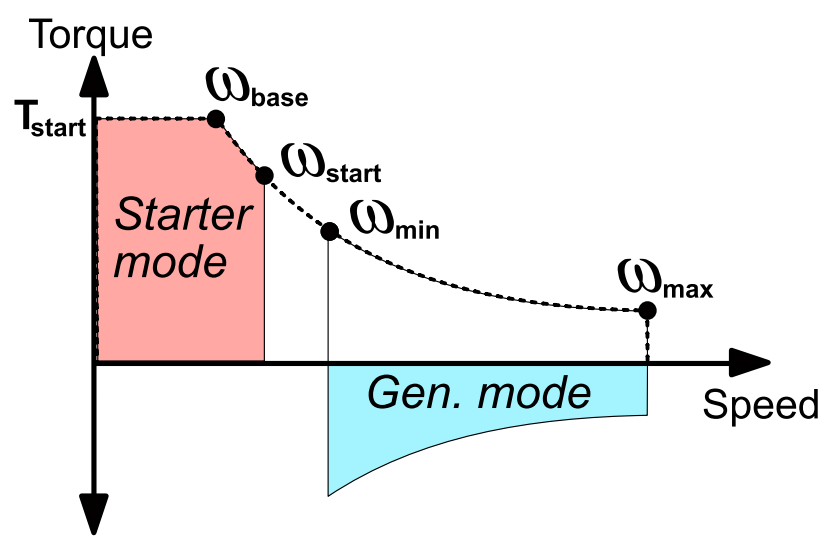

Fig. 2. General torque-speed requirements for an ideal starter-generator (S/G).

bus voltages of $270 \mathrm{~V}$ or $540 \mathrm{~V} \mathrm{dc}$ is also considered for future aircraft systems [3], [19].

\section{B. Basic principles of starter-generators $(\mathrm{S} / \mathrm{Gs})$}

A starter-generator $(\mathrm{S} / \mathrm{G})$ system must be designed for bidirectional power flow and has basically two modes of operation, as seen in Fig. 2.

- Starter mode: $S / G$ in motoring mode where the aircraft engines are behaving as a load. The starter accelerates the engine to the self-sustaining speed $\left(\omega_{\text {start }}\right)$.

- Generator mode: The engine is finally self-sustained, and the interface inverter supplies the onboard loads through constant frequency (CF), variable frequency (VF) or dc supply from variable speed (VS) operation.

In practice, the power flow is regulated by the controlled voltage source of the PEC interface. In this way, the S/G can operate in both generator mode and starter mode.

Several machine technologies have been proposed for S/G applications [7], [20], including permanent magnet machines (PMMs) [21], [22], induction machines (IMs) [23]-[25], switched reluctance machines (SRMs) [26]-[29] and brushless wound-field synchronous machines (WFSMs) [30]. Fig. 3 illustrates the basic structure and most common PEC interface of each candidate solution (assuming an AC/DC interface solution as Fig. 1b).

\section{PEC interfaces in MEA for $S / G s$}

The PEC interface of an S/G must be bidirectional, operating as an inverter in starting mode and rectifier is generation mode. The classical PEC interfaces considered for S/G applications are shown in Fig. 4. The two-level inverter employs a minimal amount of active switches, yielding simplicity and reliability. The three-level neutral-point-clamped (NPC) converter is typically considered to achieve reduced EMI emissions and higher fundamental frequency without increasing the switching frequency of the individual devices (relevant for high-speed operation). The SRM drive employs separately controlled single phases, as shown in Fig. 3 d) and Fig. 4c). 


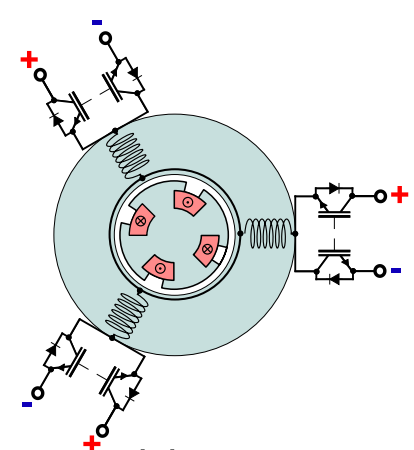

(a)

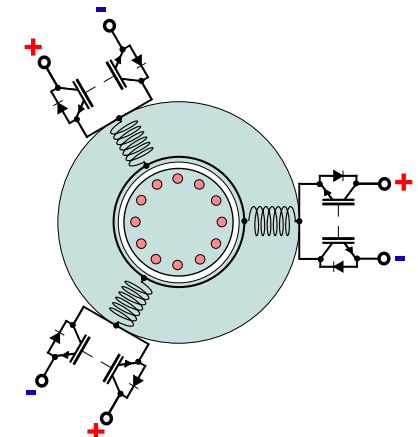

(b)

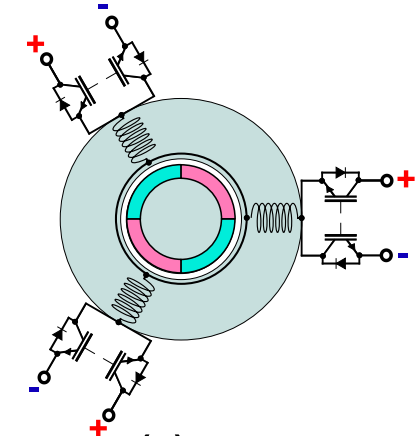

(c)

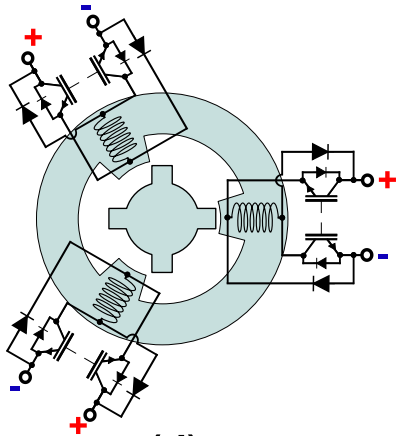

(d)

Fig. 3. Considered choices for electrical machines in more electric architectures [1] with an AC/DC interface (see Fig 1b). a) Wound-field synchronous machines (WFSMs). b) Squirrel-cage induction machines (IMs). c) Permanent magnet machines (PMMs). d) Switched reluctace machines (SRMs).

TABLE I

Summary of POWER ELECTRONIC INTERFACES FOR STARTER-GENERATORS

\begin{tabular}{|c|c|c|c|}
\hline PEC type & Merit & Weakness & Ref. \\
\hline $\begin{array}{l}\text { Two-level } \\
\text { converter }(2 L)\end{array}$ & $\begin{array}{l}\text { - Low cost and simple design (reliable); } \\
\text { - Minimum number of switches and gate drivers. }\end{array}$ & $\begin{array}{l}\text { - High voltage THD and high } d v / d t \\
\text { - Large dc side capacitor. }\end{array}$ & [31] \\
\hline $\begin{array}{l}\text { Three-level neutral point } \\
\text { clamped converter ( } 3 L-N P C)\end{array}$ & $\begin{array}{l}\text { - Reduced voltage THD and } d v / d t \text {; } \\
\text { - Higher efficiency and reduced harmonic losses. }\end{array}$ & $\begin{array}{l}\text { - Higher number of devices with uneven losses; } \\
\text { - Increased capacitor volume. }\end{array}$ & $2]$ \\
\hline Dual-quadrant converter & - Phases independently controlled. & - Exclusive technology for SRMs. & [26] \\
\hline $\begin{array}{l}\text { Indirect matrix } \\
\text { converter }(\text { IMC) }\end{array}$ & $\begin{array}{l}\text { - Light-weight PEC avoiding bulky dc-link; } \\
\text { - Direct AC-AC conversion with small filters. }\end{array}$ & $\begin{array}{l}\text { - Demands high number of switches and gate drivers; } \\
\text { - Higher output current demand (low transfer ratio). }\end{array}$ & $\begin{array}{l}{[33]} \\
{[34]}\end{array}$ \\
\hline
\end{tabular}

The configurations in Fig. 3 and Fig. 4 all assume interface to a dc capacitor, and are directly applicable for systems with dc distribution as assumed in Fig. 1 b). However, high voltage dc-distribution $(270 / 540 \mathrm{~V})$ also introduces challenges on protection systems, and depends on emerging semiconductorbased breakers [19]. Fixed frequency ac-distribution based on the presented configurations will instead require two-stage ACDC-AC PEC interfaces, which adds extra losses and hardware to the MEA system. Two avoid the two-stage conversion with the need for a large dc-capacitor, matrix converters which directly converts from $\mathrm{AC}$ to $\mathrm{AC}$ without a dc-link can be applied [5]. For instance, the use of an indirect matrix converter is proposed in [33]. These considerations argue in favour of including the high voltage dc bus (HVDC) [6]. Table I summarizes the merits and demerits of the most relevant bidirectional PEC interfaces suitable for $\mathrm{S} / \mathrm{G}$ applications.

\section{WOUND-FIELD SYNCHRONOUS MACHINE AS STARTER/GENERATOR}

Brushless WFSMs are widely used as the generator in the traditional aircraft power systems. In addition, it is the classical solution for high-power inverter-fed electric drive systems.Currently, it is a mature technology with high power density, high reliability and simple maintenance. Therefore, it is still a very attractive solution for ac aircraft power systems employing both fixed frequency and variable frequency. The main advantages are high starting capability and high power generation capability over a wide speed range for a single machine. However, the solution is not cost-competitive for smaller aerospace applications. For larger machines, it avoids

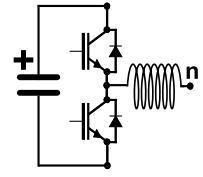

(a)

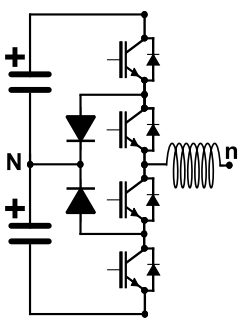

(b)

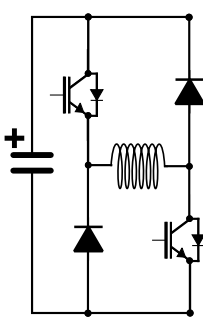

(c)
Fig. 4. Different single-stage AC/DC PEC interfaces typically used in S/Gs (one phase). a) Two-level inverter. b) Three-level neutral point clamped (NPC) inverter. c) Full-asymmetric dual-quadrant inverter (exclusively for SRMs).

the relatively high costs of PMs but at the expense of increased size and weight. As a result, it can compete with the PMMs in the market of large S/Gs. WFSMs need a dc source to supply the rotor field winding. An additional winding to be controlled in the rotor adds complexity and overall weight to the system. In addition, carbon dust from brushes and slips rings should be avoided in ultra-reliable MEA applications. As a result, a rotating transformer or a brushless exciter solution is to be adviced. A conventional exciter includes three electrical machines on the same shaft (three-stage system) [35]; The main generator (MG, the main exciter (ME) and the pilot preexciter (PE). The PE is typically a permanent magnet generator (PMG) that extends the shaft. However, it can be replaced by other auxiliary sources [36]. A conventional synchronous brushless exciter (configured as an inside-out synchronous machine) only works in generator mode, since a mechanical 
speed is required to transfer excitation power to the rotor. The ME and MG are electrically connected via a rotating diode bridge rectifier which introduces non-linearities. Without the use of rotor measurements, the MG field current is not known.

As a matter of fact, brushless exciters and rotating diode bridges add space on the shaft and thus limits the top speed of the machine. A complicated design of the whole brushless WFSM is needed to avoid mechanical failure. An upper realistic speed limit has been stated to be around $20000 \mathrm{r} / \mathrm{min}$ [37]. However, the integrated drive generator (IDG) of the Boeing 777 aircraft (first flight 1994) rotates at $24000 \mathrm{r} / \mathrm{min}$ [38]. In practice, the radial dimensions must be reduced to limit the centrifugal forces and the rotating diode rectifier is placed inside the ME rotor to save axial space.

The WFSM yields numerous possibilities in terms of optimization. It has three control variables, the d-axis stator current $\left(I_{d}\right)$, the q-axis stator current $\left(I_{q}\right)$ and the rotor field current $\left(I_{f}\right)$. The needed field current is flexible, and it can be minimized with a special design. The field current can be controlled to achieve the necessary flux weakening capability. In addition, a redundant de-excitation circuit improves the safety for the S/G [39]. This because of the possibility to cancel the fault current when short-circuits or high voltages occur. This circuitry does not depend on the PEC at the statorside, thus achieving a fail-safe solution. During high-speed flux-weakening operation, the power factor and the efficiency are still high. Synchronous rectifier operation can be applied in generator mode to reduce EMI and improve efficiency (converter losses). Its high power factor reduces the size of the inverter as well.

The ME stator and the MG stator must be controlled simultaneously during the startup process of the WFSM. Excitation boosting during startup is a great advantage of the WFSM to enhance the starting torque. This functionality demands a specially designed exciter with dedicated control methods. Increasing complexity is added since the starting mode control scheme is fundamentally different from the generation mode. Therefore, a decoupled coordinated control scheme has been recently proposed [40]. A multivariable non-linear problem must be solved in order to excite the machine properly under standstill conditions. This is because the ME and the MG are electromagnetically coupled in starting mode.

In the three next subsections, the three possible brushless asynchronous excitation (AE) methods for WFSMs in starting mode is described. The key points are then summarized in Table II.

\section{A. Single-Phase Brushless AE}

The single-phase $\mathrm{AE}$ is equivalent to a standard synchronous exciter, as illustrated in Fig. 5. However, the stator field winding can be operated with both dc and ac current. In fact, ac current is needed to excite the WFSM from standstill. However, it is limited by pulsating excitation power. In addition, the high field inductance restricts the ac current, which deteriorates the performance in starting mode. As a result, the single-phase $\mathrm{AE}$ is not sufficient for commercial starting solutions in MEA

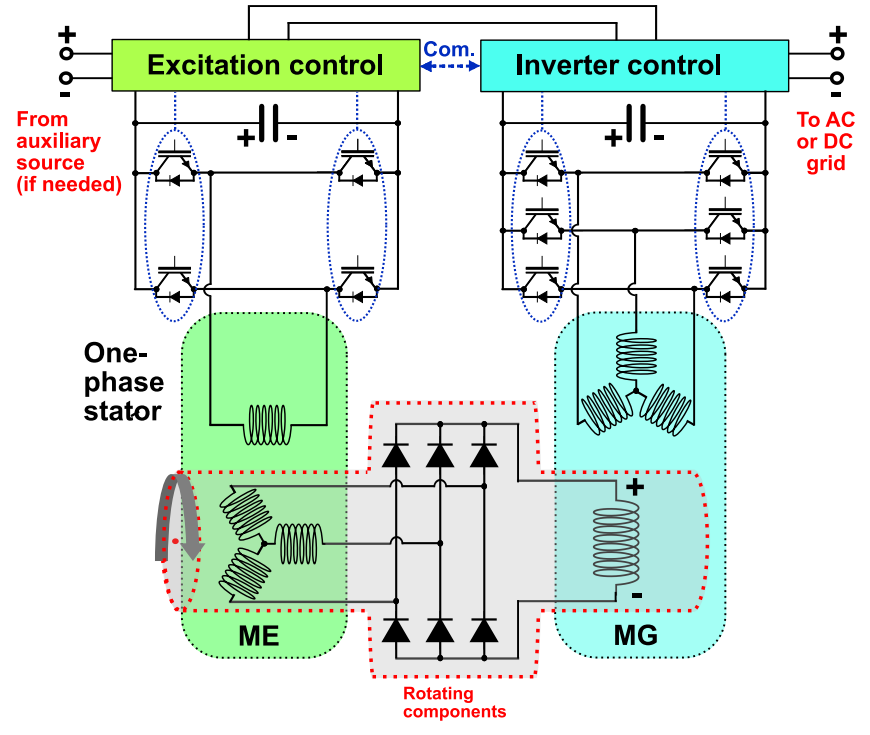

Fig. 5. Single-phase stator configuration of the asynchronous excitation system reported in [41], [42]. ME: Main exciter. MG: Main generator.

applications [36]. As the WFSM approaches enough speed, the $\mathrm{AE}$ is fed with dc current instead of pulsating ac current. The dc excitation is very easy to control, however, it is only sufficient in generator mode.

\section{B. Two-Phase Brushless AE}

The AE can be configured with two orthogonal stator phases to improve the excitation efficiency during starting mode (see Fig. 6). In this configuration, it is possible to generate a rotating magnetic flux in the $\mathrm{AE}$ from the stator-side, and the electromagnetic behaviour of the ME follows the one of an induction generator. The control of the starting phase at the MG can be fairly easy if the excitation field is kept constant. This condition can be effectively achieved by conveniently controlling the frequency of the two-phase currents at the AE, in order to keep the relative speed between the rotor and the magnetic field at the ME constant [43].

In the generator mode, dc currents feed the stator phases of the AE. Equal field current in both phases ensures a uniform thermal footprint in the stator. The generator mode becomes equal to the single-phase configuration explained in the previous paragraph.

\section{Three-Phase Brushless AE}

Fig. 6 also shows the three-phase AE that can improve the excitation transfer to the WFSM in starting mode [36], similar to the two-phase AE. The stator has three interconnected and distributions field windings, that can be fed with $\mathrm{AC}$ voltages during starting mode [45]. In practice, it functions as a three-phase rotating transformer during a generator starting condition. A rotating flux over the AE is possible using both a three-phase and a two-phase AE. In achieving simple control of the $\mathrm{AE}$ in generator mode, a dual inverter is proposed to reconnect the three-phase windings for dc excitation [46]. However, it becomes significantly more complicated than the 
TABLE II

SUMMARY OF EXCITATION CONFIGURATIONS FOR WFSM STARTER GENERATORS

\begin{tabular}{|c|c|c|c|}
\hline Exciter type & Merit & Weakness & Reference \\
\hline Single-phase AEs & $\begin{array}{l}\text { - Could utilize a standard synchronous ME; } \\
\text { - Very simple control structure in generator mode; }\end{array}$ & $\begin{array}{l}\text { - Pulsating and limited excitation in staring mode; } \\
\text { - Cannot provide high-torque starting functionality; }\end{array}$ & [41], [42] \\
\hline Two-phase AEs & $\begin{array}{l}\text { - Provides high starting torque for the WFSM; } \\
\text { - Simple control structure in generator mode; }\end{array}$ & $\begin{array}{l}\text { - Machine construction rarely used in exciters; } \\
\text { - Third leg must be oversized (basic topology) }\end{array}$ & [43], [44] \\
\hline Three-phase AEs & $\begin{array}{l}\text { - Provides high starting torque for the WFSM; } \\
\text { - The AE is a standard wound-rotor IM; }\end{array}$ & $\begin{array}{l}\text { - DC excitation demands a peculiar inverter with } 12 \text { IGBTs; } \\
\text { - AC excitation yields complex control in generator mode; }\end{array}$ & [30] \\
\hline
\end{tabular}

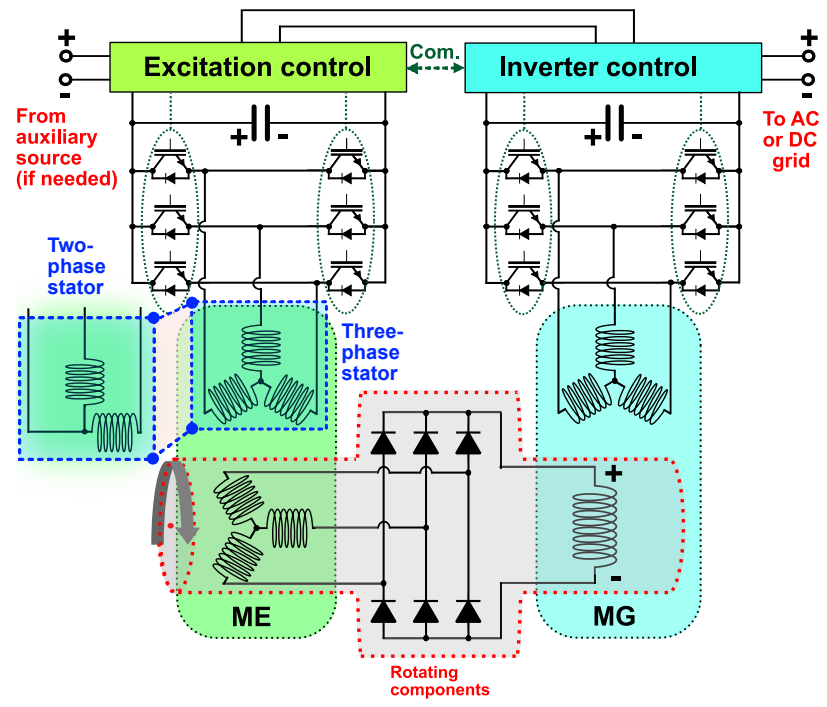

Fig. 6. Combined schematic of the two-phase stator configuration of the asynchronous excitation (AE) system [43], [44] and the three-phase stator configuration of the AE system [30]. ME: Main exciter. MG: Main generator.

two-phase AE, since all phase-windings have to be opencircuited between the inverter legs. In fact, it needs 12 IGBTS, which inevitably increases the PEC device (twice the number of switches for a two-level VSC technology).

\section{Alternative StARTER/GENERATOR CONCEPTS}

This section elaborates on the alternative solutions to WFSMs as $\mathrm{S} / \mathrm{Gs}$ in future MEA systems.

\section{A. The Induction $S / G$}

The induction machine is known as a fail-safe topology. It enjoys mechanical robustness and a low-cost construction with reduced maintenance. In general, the IM S/G is a good compromise between performance and reliability. It supports fairly high machine temperatures (up to $250^{\circ}$ ) [1]. Machine faults can be easily managed and detected. The overload capability and faulty operation has been significantly improved with a multi-phase architecture [47]. A dual stator winding set is proposed to improve the power flow of the $S / G$ [48].

During rotor failure, rotor windings or bars tend to heat up and thus reduce the efficiency. Significant rotor losses which limit the fault tolerance capability of the rotor. Another drawback is the reduced reliability and torque density during starting mode [47]. Therefore, at the stator-side, the inverter has to be oversized in order to achieve high starting torque and deliver the magnetizing current. A relatively large air gap (due to vibration) causes a significant stator current to sustain the magnetizing flux. Earlier investigations have shown the feasibility of the doubly-fed induction machine (DFIM) as an aero-generator [23]. It was primarily related to the replacement of the hydraulic constant speed drive (CSD), allowing variable speed for the engine. With an inverter at $18 \%$ of the full system rating, it could achieve this target, with no mechanical components. However, it would generally require an excitation system for the rotor based on brushes and slip rings, considering that brushless configurations [23] are based on more complex control algorithms.

\section{B. The Permanent Magnet $S / G$}

The permanent magnet machines (PMMs) have been promoted during the last decades with the emergence of stronger and less expensive magnet materials [49]. The PMM has no active components in the rotor. As a result, it has high efficiency and high power density. The maximum peak torque is available even at standstill. However, the current limits of conventional off-the-shelf PEC technology reduces the available peak torque in starting mode. In addition, high efficiency can be reached even at high $\mathrm{d}$-axis currents beyond the nominal operating point. In particular, this is true considering the fact that interior PMs results in a wider constant power zone (increases the flux weakening capability). Concentrated coil windings do also increase the field weakening capability in combination with a more fault-tolerant design.

Classical PMMs lacks the ability to provide high power over a very wide speed range, e.g., three to one range. However, a six to one range is achievable by proper design of inset PMMs. This is because a constant power zone of high efficiency and power factor is difficult to keep high as the d-current increases many orders of magnitude. In addition, there are unstable modes of operation that need rigorous considerations [50]. Other concerns relate to reliability and safety. If not designed properly, PMs always have a potential risk of demagnetization and they are especially vulnerable to demagnetization at high temperatures, corrosion and excessive short-circuit fault currents, which do not meet aerospace requirements. Therefore, the maximum demagnetization field flux must be incorporated into the design process. SamariumCobalt $\left(\mathrm{Sm}_{2} \mathrm{Co}_{17}\right)$ can survive temperatures beyond $300^{\circ} \mathrm{C}$ [51] (maybe as high as $350^{\circ} \mathrm{C}$ [52]). In general, $300^{\circ} \mathrm{C}$ should be considered as the worst case temperature for the PMM 
S/G [37]. However, it is unavoidable that high thermal stress affects the machine robustness, ageing and lifetime. In the stator, intensive cooling can significantly reduce the copper losses, which are temperature-dependent. It is perceived that an increased winding temperature of $10^{\circ} \mathrm{C}$ reduces the insulation lifetime by $50 \%$ [53]. The PMM is permanently excited, and the excitation cannot be disabled as in a WFSM. Consequently, it is fully excited at all operating speeds. As a result, it can cause excessive induced currents during a fault, with undesirable torque pulsations and thermal hot spots. There is also a concern related to possible detachment of magnets during high-speed operation [52], i.e., extra high strength retention methods (e.g. carbon fiber sleeve material) must be considered for inner rotors [37]. However, modern design of S/G PMMs employs an out-runner topology (successful R\&D performed by Rolls Royce Electrical Norway), where the rotor core basically support the PMs at the expense of higher inertia (which needs to be minimized). However, it smooths out any torque ripple.

Converter switch-off and speed overshoot can cause safety concerns. Redundant solutions in the PEC device is required. In particular, loss of PEC control at high-speed operation creates high and dangerous terminal-voltages. All voltage regulation of PMMs and fail-safe solutions must be accomplished by the PEC device. However, new solutions that are proactive to potential failures are currently under consideration. With high armature reactance in a multiphase configuration, faulttolerance can be accomplished.

\section{The Switched Reluctance $S / G$}

Switched reluctance machines (SRMs) as an aircraft $\mathrm{S} / \mathrm{G}$ is not something completely new. The fault-tolerant nature of the simple single-element rotor geometry and the concentrated windings in the stator are among its well-known merits. Consequently, the absence of magnets, bars or windings in the rotor inevitably increase the reliability of the single laminated rotor part. SRMs has superior thermal capabilities. It is worth noting that many future aircraft applications would may demand thermal design toward $500^{\circ} \mathrm{C}$. The SRM rotor has limited needs for cooling. Such considerations would permit ambient temperatures in the $400^{\circ} \mathrm{C}$ range [62]. One drawback is the fact that the salient shape of the rotor generates windage losses, which require special considerations at high speeds [62]. The gaps can be filled with non-magnetic materials, but it complicates the construction, and extra inertia is added (which smooths torque pulsations). In addition, the source of each winding can have segmented supplies, yielding safe operation even under winding faults or PEC faults. Moreover, the manufacturing costs are low, even though the SRM often uses custom-made PEC (even though off-the-shelf parts like $3 \mathrm{x}$ three-leg bridges or 3x H-bridges would be sufficient) and control algorithms. The power electronics have a similar size as used for PMMs. In practice, the SRMs has been implemented in military aircrafts like the Lockheed Martin F-22 (from 2005) and F-35 (from 2015) based on a $270 \mathrm{~V}$ dc supply [16]. It is a natural choice since military aircraft demands lower power generation than civil aviation.

Considering the MEA era, the SRM can be designed with a very wide constant power-speed range. However, the highpower SRM performs with an efficiency as low as 80-82\% [29], [51]. In fact, SRMs have comparable power density as the IMs, but lower than PM designs. Their drawback for S/G applications is the fact that they lack very high starting torque capability with conventional machine design and associated power electronics. The PEC interface is operationally more demanding than conventional drives. It has a full-asymmetric dual-quadrant bridge type for each phase, as seen in Figs. 3d) and Fig. 4c). It allows individual controllability of each phase, but high voltages ripples are observed in generator mode. Significant torque pulsations are usually an inherent property of the machine type. On the other hand, a potential loss of the PEC during high-speed operation is not a major concern, considering that the induced voltage becomes inherently zero.

\section{Discussions And CONCLUSIONS}

The purpose of this review was to revisit the trends in the research and development of starter-generators (S/Gs) in the era of MEA applications. The aim was to guide the reader in the understanding of the different aspects of the technologies involved which influences the speed of take-off of the new era of more electric aircraft. The key points of the different technologies are summarized in Table III.

The brushless WFSM with a rotating diode bridge is the most popular state-of-the-art S/G technology. It enjoys high reliability and inherent safety with a fail-safe and flexible excitation. However, its physical speed limit reduces the potential for higher power densities. The key specification of the AEGART S/G system is $32000 \mathrm{r} / \mathrm{min}$ goes beyond what current WFSM technology can deliver [37]. This paper reports that there are still ongoing research in the area of WFSM S/G systems, especially in the area of excitation systems and its associated control schemes to improve WFSM functionality.

Due to a strict request for high power density in future aviation solutions, the PM machine emerges as a strong candidate for various operations in aviation. It is worth highlighting that the AEGART project reported a power density of $16 \mathrm{~kW} / \mathrm{kg}$ based on high-speed PMM S/G technology with $4 \mathrm{~kW} / \mathrm{kg}$ for the associated PEC [37]. In fact, it was discovered that a corresponding $\mathrm{S} / \mathrm{G}$ based on SRM technology achieves approximately $1.27 \mathrm{~kW} / \mathrm{kg}$ [29], i.e. a $92 \%$ reduction. It is generally agreed that a higher speed is needed in order to take full advantage of the SRM power density potential. Generally speaking, the SRM performance is quite similar to the IM. Both have a quite high $\mathrm{kVA} / \mathrm{kW}$ ratio due to the fact that the stator winding has to produce the main magnetic flux. The WFSM has unity $\mathrm{kVA} / \mathrm{kW}$ ratio ideally for all speeds, since the excitation system handles the flux regulation (excitation power is typically about $1-2 \%$ of the WFSM rating). Intensive cooling is a straightforward method to increase power density [20]. Substantial developments are currently seen for PMMs in MEA applications. However, the other candidates presented 
TABLE III

SUMMARY OF THE ELECTRICAL MACHINES FOR STARTER-GENERATORS

\begin{tabular}{|c|c|c|c|}
\hline Machine type & Merit & Weakness & Reference \\
\hline $\begin{array}{l}\text { Wound-field } \\
\text { synchronous } \\
\text { machines } \\
(W F S M s)\end{array}$ & $\begin{array}{l}\text { - Can reduce dv/dt transients by six-step operation ; } \\
\text { - Flexible optimization by three variables }\left(I_{d}, I_{q}, I_{f}\right) \text {; } \\
\text { - Improved safety due to de-excitation ability ; } \\
\text { - Convenient voltage regulation ; } \\
\text { - High power factor at a wide speed range ; }\end{array}$ & $\begin{array}{l}\text { - More complicated control schemes; } \\
\text { - Requires an additional exciter machine (speed limit); } \\
\text { - Complex starting control methodology } \\
\text { - State-of-the-art cannot run faster than } 24000 \mathrm{r} / \mathrm{min} \\
\text { - Extra exciters compromises overall weight }\end{array}$ & $\begin{array}{l}{[41],[42]} \\
{[43],[44]} \\
{[30],[54]} \\
{[38]}\end{array}$ \\
\hline $\begin{array}{l}\text { Induction } \\
\text { machines } \\
\text { (IMs) }\end{array}$ & $\begin{array}{l}\text { - Wide speed range with efficiency greater than } 80 \% \text {; } \\
\text { - Passive rotor structure for fault tolerance; } \\
\text { - Supports high rotor temperatures up to } 250^{\circ} \mathrm{C} \\
\text { - Machine faults can be detected and managed } \\
\text { - It has natural field weakening ability }\end{array}$ & $\begin{array}{l}\text { - Reduced power at high speeds (low power factor); } \\
\text { - Magnetizing current demands an oversized converter } \\
\text { - Low torque and reliability during starting mode } \\
\text { - Significant rotor losses must be thermally managed }\end{array}$ & $\begin{array}{c}{[55],[56]} \\
{[48]}\end{array}$ \\
\hline $\begin{array}{l}\text { Permanent } \\
\text { magnet } \\
\text { machines } \\
(P M M S)\end{array}$ & $\begin{array}{l}\text { - High efficiency (despite high negative values of } I_{d} \text { ) } \\
\text { - Interior magnets achieve wide constant power zone } \\
\text { - High speed ability \& power density } \\
\text { - Low } \mathrm{kVA} / \mathrm{kW} \text { ratio for a wide speed range } \\
\text { - Compact design with low mass }\end{array}$ & $\begin{array}{l}\text { - High terminal voltage if power electronics fails; } \\
\text { - Requires supplementary protection system for safety } \\
\text { - Risk of irreversible demagnetization } \\
\text { - De-excitation reliability problem under fault condition } \\
\text { - High strength magnet retention needed for high speeds }\end{array}$ & $\begin{array}{c}{[21],[57]} \\
{[22],[58]} \\
{[50],[59]} \\
{[37]}\end{array}$ \\
\hline $\begin{array}{l}\text { Switched } \\
\text { reluctance } \\
\text { machines } \\
(S R M s)\end{array}$ & $\begin{array}{l}\text { - Robust technology convenient for high-speed; } \\
\text { - Superior fault-tolerance for a harsh environment } \\
\text { - One-material rotor is easy to manufacture } \\
\text { - Inherent overcurrent protection } \\
\text { - Wide torque-speed envelope in motoring mode }\end{array}$ & $\begin{array}{l}\text { - Low efficiency and significant torque pulsations; } \\
\text { - High-voltage ripples in generator mode } \\
\text { - Needs custom-built power electronics design } \\
\text { - Require precise rotor position monitoring } \\
\text { - Depend on accurate control algorithms }\end{array}$ & $\begin{array}{c}{[26],[60]} \\
{[29],[29]} \\
{[61]}\end{array}$ \\
\hline
\end{tabular}

in this paper are still relevant mainly due to their state-ofthe-art fault tolerances, reliability and inherent safety. Current methodologies aim at optimizing both PECs and electrical machines in a coupled multi-physical environment [37], in a way to overcome the disadvantages of the particular machinetype in focus. For the S/Gs, in particular, future research would benefit from a strong focus on how to design;

- Safe and reliable machines with super-high power density.

- High peak torque capability in starting mode.

- High-voltage solutions for high elevations (beyond $3 \mathrm{kV}$ ).

- Intensive cooling that integrates machine with PEC.

- Efficient high-frequency PEC for ultra-high speeds.

- Fault-tolerant and high-temperature solutions for PMMs.

Designing optimal component technologies and materials is not going to be the way to conceive better MEA systems because of the many conflicting objectives in the different parts of the system. A call for new design methodologies is advocated in this review. Tools for the optimal and global design of multi-physics systems will benefit the take-off of the MEA initiative by reducing the time of conception and the numbers of prototypes before the final product. These tools will need to include and couple electrical, magnetic and thermal design simulations to capture the accurate behaviour of the various physical components and the system overall. The possible new paths and evolution of possibilities will emerge from this global approach in pace with the ongoing advancements in the different parts of the systems.

\section{REFERENCES}

[1] G. Friedrich and A. Girardin, "Integrated starter generator," IEEE Ind. Appl. Mag., vol. 15, no. 4, pp. 26-34, July 2009.

[2] B. S. Bhangu and K. Rajashekara, "Electric starter generators: Their integration into gas turbine engines," IEEE Ind. Appl. Mag., vol. 20, no. 2, pp. 14-22, March 2014.

[3] V. Madonna, P. Giangrande, and M. Galea, "Electrical power generation in aircraft: Review, challenges, and opportunities," IEEE Trans. Transp. Electrific., vol. 4, no. 3, pp. 646-659, Sep. 2018.
[4] J. Chen, C. Wang, and J. Chen, "Investigation on the selection of electric power system architecture for future more electric aircraft," IEEE Trans. Transport. Electrific., vol. 4, no. 2, pp. 563-576, June 2018.

[5] B. Rahrovi and M. Ehsani, "A review of the more electric aircraft power electronics," in Proc. IEEE Texas Power and Energy Conf. (TPEC), Feb 2019, pp. 1-6.

[6] G. Buticchi, S. Bozhko, M. Liserre, P. Wheeler, and K. Al-Haddad, "On-board microgrids for the more electric aircrafttechnology review," IEEE Trans. Ind. Electron., vol. 66, no. 7, pp. 5588-5599, July 2019.

[7] K. Ni, Y. Liu, Z. Mei, T. Wu, Y. Hu, H. Wen, and Y. Wang, "Electrical and electronic technologies in more-electric aircraft: A review," IEEE Access, vol. 7, pp. 76 145-76 166, 2019.

[8] V. Madonna, A. Walker, P. Giangrande, G. Serra, C. Gerada, and M. Galea, "Improved thermal management and analysis for stator endwindings of electrical machines," IEEE Trans. Ind. Electron., vol. 66, no. 7, pp. 5057-5069, July 2019.

[9] V. Madonna, P. Giangrande, L. Lusuardi, A. Cavallini, C. Gerada, and M. Galea, "Thermal overload and insulation aging of short duty cycle, aerospace motors," IEEE Trans. Ind. Electron., pp. 1-1, 2019.

[10] S. Yin, K. J. Tseng, R. Simanjorang, Y. Liu, and J. Pou, "A 50-kw high-frequency and high-efficiency sic voltage source inverter for more electric aircraft," IEEE Trans. Ind. Electron., vol. 64, no. 11, pp. 9124 9134, Nov 2017.

[11] J. Wei, H. Xu, B. Zhou, Z. Zhang, and C. Gerada, "An integrated method for three-phase ac excitation and high-frequency voltage signal injection for sensorless starting of aircraft starter/generator," IEEE Trans. Ind. Electron., vol. 66, no. 7, pp. 5611-5622, July 2019.

[12] A. Griffo, D. Drury, T. Sawata, and P. H. Mellor, "Sensorless starting of a wound-field synchronous starter/generator for aerospace applications," IEEE Trans. Ind. Electron., vol. 59, no. 9, pp. 3579-3587, Sep. 2012.

[13] E. D. Ganev, "High-performance electric drives for aerospace more electric architectures part i - electric machines," in Proc. IEEE Power Eng. Soc. Gen. Meeting, June 2007, pp. 1-8.

[14] S. F. Clark, "787 propulsion system," Aero Quarterly, no. 3, pp. 5-13, 2012.

[15] A. Hyder, "A century of aerospace electrical power technology," $J$. propulsion and power, vol. 19, no. 6, pp. 1155-1179, 2003.

[16] I. Moir and A. Seabridge, Aircraft Systems: Mechanical, electrical, and avionics subsystems integration. John Wiley \& Sons, 2011, vol. 52.

[17] J. Weimer, "Past, present and future of aircraft electrical power systems," in Proc. 39th Aerospace Sciences Meeting and Exhibit, 2013, p. 1147.

[18] S. S. Yeoh, M. Rashed, M. Sanders, and S. Bozhko, "Variable-voltage bus concept for aircraft electrical power system," IEEE Trans. Ind. Electron., vol. 66, no. 7, pp. 5634-5643, July 2019.

[19] D. Izquierdo, A. Barrado, C. Raga, M. Sanz, and A. Lazaro, "Protection devices for aircraft electrical power distribution systems: State of the 
art," IEEE Trans. Aerosp. Electron. Syst., vol. 47, no. 3, pp. 1538-1550, July 2011.

[20] X. Zhang, C. L. Bowman, T. C. O'Connell, and K. S. Haran, "Large electric machines for aircraft electric propulsion," IET Elect. Power Appl., vol. 12, no. 6, pp. 767-779, 2018.

[21] L. Alberti, M. Barcaro, M. D. Pre, A. Faggion, L. Sgarbossa, N. Bianchi, and S. Bolognani, "Ipm machine drive design and tests for an integrated starter-alternator application,” IEEE Trans. Ind. Appl., vol. 46, no. 3, pp. 993-1001, May 2010.

[22] M. C. Kulan, N. J. Baker, and J. D. Widmer, "Design and analysis of compressed windings for a permanent magnet integrated starter generator," IEEE Trans. Ind. Appl., vol. 53, no. 4, pp. 3371-3378, July 2017.

[23] T. Feehally and J. M. Apsley, "The doubly fed induction machine as an aero generator," IEEE Trans. Ind. Appl., vol. 51, no. 4, pp. 3462-3471, July 2015.

[24] Y. Jia and K. Rajashekara, "An induction generator-based ac/dc hybrid electric power generation system for more electric aircraft," IEEE Trans. Ind. Appl., vol. 53, no. 3, pp. 2485-2494, May 2017.

[25] — " "Induction machine for more electric aircraft: Enabling new electrical power system architectures," IEEE Electrific. Mag., vol. 5, no. 4, pp. 25-37, Dec 2017.

[26] C. A. Ferreira, S. R. Jones, W. S. Heglund, and W. D. Jones, "Detailed design of a 30-kw switched reluctance starter/generator system for a gas turbine engine application," IEEE Trans. Ind. Appl., vol. 31, no. 3, pp. 553-561, May 1995.

[27] P. H. Mellor, S. G. Burrow, T. Sawata, and M. Holme, "A wide-speedrange hybrid variable-reluctance/permanent-magnet generator for future embedded aircraft generation systems," IEEE Trans. Ind. Appl., vol. 41, no. 2, pp. 551-556, March 2005.

[28] S. G. Burrow, P. H. Mellor, P. Churn, T. Sawata, and M. Holme, "Sensorless operation of a permanent-magnet generator for aircraft," IEEE Trans. Ind. Appl., vol. 44, no. 1, pp. 101-107, Jan 2008.

[29] J. Borg Bartolo, M. Degano, J. Espina, and C. Gerada, "Design and initial testing of a high-speed $45-\mathrm{kw}$ switched reluctance drive for aerospace application," IEEE Trans. Ind. Electron., vol. 64, no. 2, pp. 988-997, Feb 2017.

[30] Z. Zhang, W. Liu, D. Zhao, S. Mao, T. Meng, and N. Jiao, "Steadystate performance evaluations of three-phase brushless asynchronous excitation system for aircraft starter/generator," IET Elect. Power Appl., vol. 10, no. 8, pp. 788-798, 2016.

[31] H. Dehghani Tafti, A. I. Maswood, Z. Lim, G. H. P. Ooi, and P. H. Raj, "Proportional-resonant controlled npc converter for more-electricaircraft starter-generator,' in Proc. Int. Conf. Power Electron. Drive Syst., June 2015, pp. 41-46.

[32] M. Schweizer, T. Friedli, and J. W. Kolar, "Comparative evaluation of advanced three-phase three-level inverter/converter topologies against two-level systems," IEEE Trans. Ind. Electron., vol. 60, no. 12, pp. 5515-5527, 2012.

[33] J. Lei, B. Zhou, J. Wei, X. Qin, and J. Bian, "Aircraft starter/generator system based on indirect matrix converter," in Proc. 40th Annual Conf. IEEE Ind. Electron. Soc., Oct 2014, pp. 4840-4846.

[34] M. Aten, G. Towers, C. Whitley, P. Wheeler, J. Clare, and K. Bradley, "Reliability comparison of matrix and other converter topologies," IEEE Trans. Aerosp. Electron. Syst., vol. 42, no. 3, pp. 867-875, July 2006.

[35] D. N. Taneja, H. Huang, G. A. Padgett, J. Zywot, P. J. Wirsch Jr, and M. A. Abbas, "Dual-structured aircraft engine starter/generator," Mar. 30 2010, US Patent App. 7/687,928.

[36] A. Griffo, R. Wrobel, P. H. Mellor, and J. M. Yon, "Design and characterization of a three-phase brushless exciter for aircraft starter/generator," IEEE Trans. Ind. Appl., vol. 49, no. 5, pp. 2106-2115, Sep. 2013.

[37] S. Bozhko and et. al., "Development of aircraft electric startergenerator system based on active rectification technology," IEEE Trans. Transport. Electrific., vol. 4, no. 4, pp. 985-996, Dec 2018.

[38] L. Andrade and C. Tenning, "Design of boeing 777 electric system," IEEE Aerosp. Electron. Syst. Mag., vol. 7, no. 7, pp. 4-11, July 1992.

[39] J. K. Nøland, S. Nuzzo, A. Tessarolo, and E. F. Alves, "Excitation system technologies for wound-field synchronous machines: Survey of solutions and evolving trends," IEEE Access, vol. PP, no. 99, pp. 1-1, 2019.

[40] N. Jiao, W. Liu, T. Meng, C. Sun, and Y. Jiang, "Decoupling control for aircraft brushless wound-rotor synchronous starter-generator in the starting mode," J. Engineering, vol. 2018, no. 13, pp. 581-586, 2018.

[41] A. Maalouf, L. Idkhajine, S. L. Ballois, and E. Monmasson, "Field programmable gate array-based sensorless control of a brushless syn- chronous starter generator for aircraft application," IET Elect. Power Appl., vol. 5, no. 1, pp. 181-192, January 2011.

[42] J. Pang, W. Liu, N. Jiao, J. Wang, and P. Ma, "Calculation of crosscoupling inductance and electromagnetic torque in wound-rotor synchronous starter/generator," IEEE Trans. Ind. Electron.s, vol. 66, no. 7, pp. 5115-5123, July 2019.

[43] N. Jiao, W. Liu, T. Meng, J. Peng, and S. Mao, "Design and control of a two-phase brushless exciter for aircraft wound-rotor synchronous starter/generator in the starting mode," IEEE Trans. Power Electron., vol. 31 , no. 6 , pp. 4452-4461, June 2016.

[44] — - "Detailed excitation control methods for two-phase brushless exciter of the wound-rotor synchronous starter/generator in the starting mode," IEEE Trans. Ind. Appl., vol. 53, no. 1, pp. 115-123, Jan 2017.

[45] N. Jiao, W. Liu, Z. Zhang, T. Meng, J. Peng, and Y. Jiang, "Field current estimation for wound-rotor synchronous startergenerator with asynchronous brushless exciters," IEEE Trans. Energy Convers., vol. 32, no. 4, pp. 1554-1561, Dec 2017.

[46] J. Wei, Q. Zheng, M. Shi, B. Zhou, and J. Li, "The excitation control strategy of the three-stage synchronous machine in the start mode," in Proc. IEEE Applied Power Electron. Conf. Expo., March 2014, pp. 2469-2474.

[47] R. Bojoi, A. Cavagnino, A. Tenconi, and S. Vaschetto, "Control of shaft-line-embedded multiphase starter/generator for aero-engine," IEEE Trans. Ind. Electron., vol. 63, no. 1, pp. 641-652, Jan 2016.

[48] H. Liu, F. Bu, W. Huang, L. Liu, Y. Hu, M. Degano, and C. Gerada, "Control strategy for five-phase dual-stator winding induction starter/generator system," IEEE Trans. Ind. Electron., pp. 1-1, 2019.

[49] E. Ganev, "Selecting the best electric machines for electrical powergeneration systems: High-performance solutions for aerospace more electric architectures." IEEE Electrific. Mag., vol. 2, no. 4, pp. 13-22, Dec 2014

[50] S. Bozhko, M. Rashed, C. I. Hill, S. S. Yeoh, and T. Yang, "Fluxweakening control of electric startergenerator based on permanentmagnet machine," IEEE Trans. Transp. Electrific., vol. 3, no. 4, pp. 864-877, Dec 2017.

[51] S. Li, S. Zhang, T. G. Habetler, and R. G. Harley, "Modeling, design optimization, and applications of switched reluctance machinesa review," IEEE Trans. Ind. Appl., vol. 55, no. 3, pp. 2660-2681, May 2019.

[52] C. R. Avery, S. G. Burrow, and P. H. Mellor, "Electrical generation and distribution for the more electric aircraft," in Proc. 42nd Int. Universities Power Eng. Conf., Sep. 2007, pp. 1007-1012.

[53] J. Bryan, Service factor: What is it and what does it do?, 2015.

[54] J. F. Gieras, "Multimegawatt synchronous generators for airborne applications: A review," in Proc. Int. Electr. Mach. Drives Conf., May 2013, pp. 626-633.

[55] I. Alan and T. A. Lipo, "Starter/generator employing resonant-converterfed induction machine. I. analysis," IEEE Trans. Aerospace Electron. Syst., vol. 36, no. 4, pp. 1309-1328, Oct 2000.

[56] _ "Starter/generator employing resonant-converter-fed induction machine. II. hardware prototype," IEEE Trans. Aerospace Electron. Syst., vol. 36, no. 4, pp. 1319-1329, Oct 2000.

[57] M. Tosetti, P. Maggiore, A. Cavagnino, and S. Vaschetto, "Conjugate heat transfer analysis of integrated brushless generators for more electric engines," IEEE Trans. Ind. Appl., vol. 50, no. 4, pp. 2467-2475, July 2014.

[58] M. C. Kulan and N. J. Baker, "Development of a thermal equivalent circuit to quantify the effect of thermal paste on heat flow through a permanent magnet alternator," IEEE Trans. Ind. Appl., vol. 55, no. 2, pp. 1261-1271, March 2019.

[59] Z. Zhang, J. Huang, Y. Jiang, W. Geng, and Y. Xu, "Overview and analysis of pm starter/generator for aircraft electrical power systems," CES Trans. Elect. Mach. Syst., vol. 1, no. 2, pp. 117-131, 2017.

[60] V. Valdivia, R. Todd, F. J. Bryan, A. Barrado, A. Lzaro, and A. J. Forsyth, "Behavioral modeling of a switched reluctance generator for aircraft power systems," IEEE Trans. Ind. Electron., vol. 61, no. 6, pp. 2690-2699, June 2014.

[61] K. Vijayakumar, R. Karthikeyan, S. Paramasivam, R. Arumugam, and K. N. Srinivas, "Switched reluctance motor modeling, design, simulation, and analysis: A comprehensive review," IEEE Trans. Magnetics, vol. 44, no. 12, pp. 4605-4617, Dec 2008.

[62] S. R. MacMinn and W. D. Jones, "A very high speed switched-reluctance starter-generator for aircraft engine applications," in Proc. IEEE Nat. Aerosp. Electron. Conf. IEEE, 1989, pp. 1758-1764. 